\title{
FOTOCATÁLISE ELETROQUÍMICA DE ATRAZINA SOBRE DIÓXIDO DE TITÂNIO: EFEITO DE DIFERENTES PARÂMETROS EXPERIMENTAIS
}

\author{
Henrique de Santana*, Carlos Eduardo Bonancêa e Keiko Takashima
}

Departamento de Química, Centro de Ciências Exatas, Universidade Estadual de Londrina, CP 6001, 86051-970 Londrina - PR

Recebido em 13/9/02; aceito em 17/4/03

\begin{abstract}
PHOTOELECTROCHEMICAL DEGRADATION OF ATRAZINA ON TITANIUM DIOXIDE: EFFECT OF DIFFERENT EXPERIMENTAL PARAMETERS. The atrazine photoelectrochemical degradation has been examined in solutions containing $\mathrm{TiO}_{2}$ on immobilized films under a variety of experimental conditions. It was possible to observe that the supporting electrolyte nature affects the intensity of the photocurrent, being an indicative of the adsorption process. The disappearance of the organic molecule follows approximately a pseudo-first order kinetic. As mineralization product, $\mathrm{NH}_{4}{ }^{+}$and $\mathrm{NO}_{3}$ - ion have been identified. These results indicated that the formation of $\mathrm{NH}_{4}{ }^{+}$ion can be associated to the effect of atrazine adsorption, due to need of potential adaptation together with a variation in the supporting electrolyte concentration.
\end{abstract}

Keywords: photoelectrocatalytic degradation; $\mathrm{TiO}_{2}$; atrazine.

\section{INTRODUÇÃO}

A atrazina (2-cloro-4-etilamino-6-isopropilamino-1,3,5-triazina), Figura 1, é usada como um herbicida nas culturas de algodão, milho, soja, feijão, abacaxi, sorgo, cana-de-açúcar e no preparo de áreas para o plantio. Suas principais características como herbicida são alto potencial de lixiviamento, lenta reação de hidrólise, baixa pressão de vapor e moderada solubilidade em água $\left(30 \mathrm{mg} \mathrm{L}^{-1}\right)$. A toxicidade de atrazina é bastante alta para os seres vivos ${ }^{1}$.

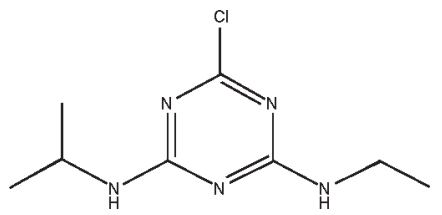

Figura 1. Estrutura química da atrazina

Arántegui et $a l .^{2}$ em seu trabalho sobre a degradação de atrazina por radiação ultravioleta mostrou que os produtos formados são igualmente tóxicos. Assim, a busca de um método eficaz para a degradação da atrazina a produtos inofensivos ao meio ambiente, os chamados "Processos Oxidativos Avançados" (POA), vêm atraindo grande interesse da comunidade científica. Esse processo é baseado na formação de radicais hidroxila que, por serem agentes altamente reativos, promovem a mineralização de compostos orgânicos ${ }^{3}$. Os POA dividem-se em sistemas heterogêneos e homogêneos, onde radicais são gerados com ou sem irradiação ultravioleta. Entre estes, pode-se citar como heterogêneos os processos que envolvem a utilização de semicondutores (fotocatálise heterogênea).

Dentre os óxidos metálicos semicondutores como $\mathrm{TiO}_{2}, \mathrm{ZnO}$, $\mathrm{WO}_{3}, \mathrm{SrTiO}_{3}$ e $\mathrm{Fe}_{2} \mathrm{O}_{3}$, o TiO 2 é o mais freqüentemente utilizado, por ser considerado bastante ativo na fotocatálise de degradação de substâncias orgânicas, na forma de suspensões aquosas ${ }^{4}$.

*e-mail: hensan@uel.br
O princípio da fotocatálise heterogênea envolve a ativação do semicondutor, $\mathrm{TiO}_{2}$, por luz solar ou artificial. A absorção de fótons com energia superior à energia de "bandgap" resulta na promoção de um elétron da banda de valência para a banda de condução, gerando uma lacuna na banda de valência e elétrons na banda de condução. As lacunas mostram potenciais suficientemente positivos para gerar radicais hidroxila, a partir de moléculas de água adsorvidas na superfície do semicondutor, os quais podem, conseqüentemente, oxidar contaminantes orgânicos 3,5 .

As degradações que utilizam suspensões de $\mathrm{TiO}_{2}$ são experimentalmente muito trabalhosas pois levam à necessidade de sucessivas filtrações para separação dos produtos da reação e o óxido. A fixação do catalisador num suporte estacionário torna a técnica mais prática, eliminando a etapa de filtração. Desta forma, podem ser confeccionados dispositivos do tipo reator tubular de vidro $^{6}$ e membranas cerâmicas ${ }^{7}$ adequados para criar um sistema fechado de tratamento de águas.

Vinodgopal et al. ${ }^{8}$ descreveram um método conveniente para acelerar a reação de fotodegradação do 4-clorofenol, pela aplicação de um potencial externo sobre eletrodos recobertos com filmes particulados de $\mathrm{TiO}_{2}$. A cela eletroquímica contendo o 4-clorofenol em solução de $\mathrm{NaOH} 0,05$ mol.L $\mathrm{L}^{-1}$ era irradiada por uma lâmpada UV e sobre o eletrodo contendo $\mathrm{TiO}_{2}$ era mantido um potencial anódico de 0,6 V(ECS).

A degradação fotocatalítica da atrazina sobre $\mathrm{TiO}_{2}$ ocorre através de uma série de etapas complexas ${ }^{9}$. Alguns intermediários têm sido identificados e o principal produto formado é o ácido cianúrico. Os dois nitrogênios remanescentes dos grupos substituintes alquilamino na molécula de atrazina formam, após longos períodos de irradiação, os íons $\mathrm{NO}_{3}^{-}$e $\mathrm{NH}_{4}^{+}$.

Muitos dos trabalhos atualmente descritos na literatura consideram separadamente os seguintes parâmetros: intensidade da radiação ultravioleta ${ }^{10}$, tempo de irradiação ${ }^{11}, \mathrm{TiO}_{2}$ dopado com diferentes íons metálicos de transição ${ }^{12}$, natureza e espessura do filme de $\mathrm{TiO}_{2}{ }^{13}$, influência do potencial aplicado ${ }^{14}$ e influência do $\mathrm{pH}^{14,15}$, com o objetivo de aumentar a eficiência do processo catalítico. No entanto, fatores que influenciam na adsorção da espécie estudada sobre o eletrodo de $\mathrm{TiO}_{2}$ não têm sido abordados.

Neste trabalho são apresentadas as evidências do comportamento fotoeletroquímico do filme de óxido de titânio em diferentes eletrólitos, 
na presença ou na ausência de atrazina, as quais comprovam a adsorção do herbicida. São apresentados os efeitos de alguns parâmetros estudados sobre a degradação e a mineralização da atrazina.

\section{PARTE EXPERIMENTAL}

Em todos os experimentos foram utilizados reagentes P. A. e água Milli-Q.

\section{Preparação do filme particulado de $\mathrm{TiO}_{2}$}

Foi preparada uma solução com $0,39 \mathrm{~mL}$ de $\mathrm{NH}_{4} \mathrm{OH}$ e $0,34 \mathrm{~mL}$ de $\mathrm{H}_{2} \mathrm{O}_{2}$, diluídos para $10 \mathrm{~mL}$ com água deionizada (Milli-Q). Esta solução foi adicionada a $0,70 \mathrm{~g}$ de $\mathrm{TiO}_{2}$ em um béquer de $25 \mathrm{~mL}$ e aquecida até formação de gel a $75{ }^{\circ} \mathrm{C}$, sob agitação magnética por $\sim 2$ h conforme descrito por Natarajan e Nogami ${ }^{16}$. Para aumentar a fluidez do gel, foram adicionadas 3 gotas de Triton X-100 e 7 gotas de acetilacetona, conforme descrito por Nazeeruddin et $a l^{17}$. A emulsão formada foi cuidadosamente depositada sobre vidro condutor ITO (óxido de estanho dopado com índio) sobre uma área de aproximadamente $\sim 2,41 \mathrm{~cm}^{2}$. Após a secagem dos filmes em estufa a $70{ }^{\circ} \mathrm{C}$ por $20 \mathrm{~min}$, foram levados a uma mufla e sinterizadas a $400{ }^{\circ} \mathrm{C}$ por $4 \mathrm{~h}$. Uma segunda camada de dióxido de titânio também foi depositada sobre alguns vidros condutores para verificar o efeito da espessura de $\mathrm{TiO}_{2}$ depositado na degradação da atrazina.

\section{Câmara de irradiação}

Para a realização do experimento foi montada uma câmara de irradiação, conforme ilustrada na Figura 2. A lâmpada de vapor de Hg (com $100 \mathrm{~W}$ da Toshiba, modelo SHL-100UVQ, com uma larga banda de emissão no UV e Vis) foi fixada num suporte (A) na base sobre o qual foi colocado um anteparo móvel entre a lâmpada e a cela eletroquímica. Um ventilador colocado neste suporte dissipa o calor gerado pela lâmpada. Na parte frontal da câmara foi colocada uma cortina para evitar a passagem de luz. Em todos os experimentos com irradiação, a solução foi deaerada continuamente através do borbulhamento com $\mathrm{N}_{2}$. A cela eletroquímica, envolta por uma camisa de vidro, foi refrigerada com a circulação de água proveniente do banho termostático (com refrigeração da Microquímica modelo MQBTC99-20) e a temperatura mantida em torno de $25 \pm 1^{\circ} \mathrm{C}$ (pois a intensidade da fotocorrente é alterada em função da temperatura). A temperatura da solução foi medida com o termopar equipado com leitor digital.

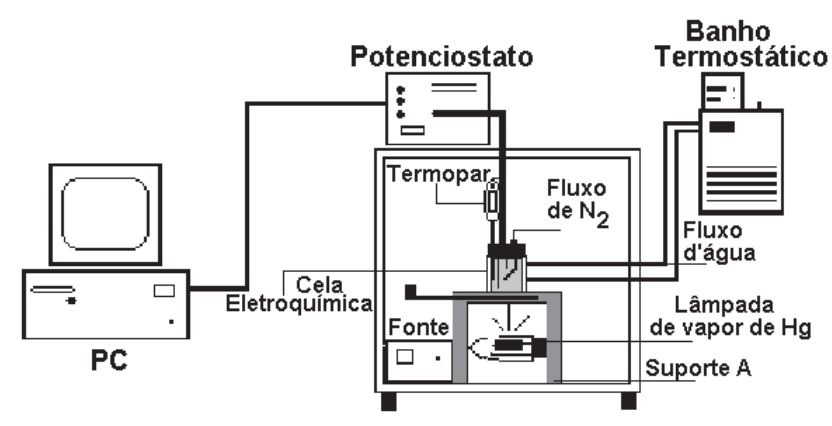

Figura 2. Arranjo experimental para fotocatálise eletroquímica

\section{Medidas eletroquímicas}

As medidas de voltametria cíclica e fotoeletroquímica foram realizadas em uma cela com único compartimento, onde foram dispos- tos adequadamente os eletrodos de referência $(\mathrm{Ag} / \mathrm{AgCl})$, auxiliar (platina) e o de trabalho (ITO- $\mathrm{TiO}_{2}$ ) e conectados ao Potenciostato (Microquímica modelo MQPG-01 acoplado ao microcomputador PC com sistema de aquisição e tratamento de dados).

\section{Determinação da concentração de atrazina fotodegradada}

Amostras de 0,4 mL foram coletadas em intervalos de tempo pré-determinados e a fotodegradação da atrazina foi acompanhada por cromatografia líquida de alta eficiência com detector UV-Vis (CLAE da Shimadzu modelo ClassLG10), utilizando-se a coluna Hypersil C-18 de 25 x 0,4 mm com fase móvel formada por acetonitrila e água na razão de 50:50 (v/v), a uma vazão de 1,0 $\mathrm{mL} \mathrm{min}^{-1}$, a $35{ }^{\circ} \mathrm{C}$ e monitorado a $220 \mathrm{~nm}$.

\section{Determinação da concentração de $\mathrm{NH}_{4}^{+}$}

A concentração do íon amônio formado após $8 \mathrm{~h}$ de fotodegradação foi determinada espectrofotometricamente pelo método de Berthelot modificado ${ }^{18}$. O método consiste na reação do íon $\mathrm{NH}_{4}^{+}$ com hipoclorito e salicilato em meio alcalino, catalisado pelo íon nitropruciato. O composto formado tem absorvância máxima em $694 \mathrm{~nm}$.

\section{Determinação da concentração de $\mathrm{NO}_{3} \cdot$}

A concentração do íon nitrato formado após $8 \mathrm{~h}$ de fotodegradação foi determinada espectrofotometricamente pelo método de redução em coluna de cádmio amalgamado com $\mathrm{Cu}^{19}$. O nitrito assim produzido é determinado espectrofotometricamente por diazotação com sulfanilamida e acoplado com N-(1-naftil)-etilenodiamida dihidrocloreto. $\mathrm{O}$ azo composto formado tem absorvância máxima em $543 \mathrm{~nm}$.

\section{RESULTADOS E DISCUSSÃO}

Quando a atrazina é irradiada com o mesmo comprimento de onda no qual é observado sua absorção no espectro UV-Vis, iniciase um processo de degradação exclusivamente fotoquímico, com baixo rendimento para se utilizar como técnica cuja finalidade é o tratamento de águas. Assim, inicialmente serão discutidas as condições experimentais para evitar este processo.

A lâmpada de vapor de mercúrio, utilizada como fonte de excitação, apresentou raias de emissão entre 185 e 580 nm. Neste intervalo de emissão, a atrazina absorve radiação em 225 e $270 \mathrm{~nm}$, como foi observado no espectro UV-Vis da atrazina. Neste contexto, a emissão da lâmpada de $\mathrm{Hg}$ abaixo de $290 \mathrm{~nm}$ leva à indesejada degradação fotoquímica da atrazina. Este problema foi contornado utilizando-se uma cela de vidro do tipo Pyrex ${ }^{\circledR}$ para filtrar a radiação no intervalo de absorção da atrazina, ou seja, de 200 a 300 nm.

Nesta cela, a solução contendo atrazina foi irradiada e foram coletadas alíquotas de solução em intervalos de tempo pré-determinados. Os espectros de absorção de solução de atrazina na região do UV-Vis em função do tempo de irradiação apresentaram-se reprodutíveis após 120 min de irradiação, indicando a não decomposição fotoquímica da atrazina.

Para ocorrer o processo fotocatalítico no filme de $\mathrm{TiO}_{2}$, este deve ser excitado com uma energia superior a $3,2 \mathrm{eV}(\lambda>386 \mathrm{~nm})$, que é a energia do "gap" entre as bandas de valência e condução. Entretanto, como foi observado no espectro de absorção do Pyrex ${ }^{\circledR}$, esta radiação não foi absorvida pelo vidro. Neste contexto, a intensa emissão da lâmpada de vapor de $\mathrm{Hg}$ acima de $300 \mathrm{~nm}$ é adequada para excitar o $\mathrm{TiO}_{2}$, sem degradar fotoquimicamente a atrazina em solução. 
Para Vinodgopal et al. ${ }^{8}$, durante os processos de irradiação do sistema ITO-TiO 2 pode ocorrer o fenômeno de recombinação do par elétron/buraco. Para evitar esta recombinação, aplica-se um potencial de oxidação ao eletrodo de trabalho e induz-se a formação de uma superfície oxidante. Foi comprovado, através de experimento da medida do potencial de equilíbrio do sistema ITO-TiO $/ \mathrm{Na}_{2} \mathrm{SO}_{4}$, que a irradiação do eletrodo desloca o potencial de equilíbrio para valores mais catódicos (de $-0,20$ para $-0,65 \mathrm{~V}$ ), ou seja, mais redutores. Desta forma, é necessária a aplicação de um potencial eletroquímico sobre o eletrodo de trabalho para tornar a superfície carregada positivamente, de modo a que possa receber os elétrons provenientes das espécies em solução.

O comportamento eletroquímico do sistema $\mathrm{ITO}^{-\mathrm{TiO}_{2}}$ foi investigado por voltametria cíclica em soluções de diferentes eletrólitos: $\mathrm{KI}, \mathrm{KCl}$ e $\mathrm{Na}_{2} \mathrm{SO}_{4}$, na ausência de herbicida. Em solução de $\mathrm{KI}$ $0,1 \mathrm{~mol} \mathrm{~L}^{-1}$ pode ser observada a presença de uma corrente anódica em $0,45 \mathrm{~V}$, devido à reação de desprendimento de oxigênio. Os dois outros eletrólitos apresentaram a reação eletroquímica de oxidação após o potencial de 1,0 V. Foi observado que, para os três eletrólitos suporte, no intervalo de 0,00 a $0,30 \mathrm{~V}$ não se observam reações de oxidação ou redução.

$\mathrm{O}$ comportamento do eletrodo ITO- $\mathrm{TiO}_{2}$ nos três eletrólitos foi acompanhado através da variação da corrente gerada em função do tempo com e sem irradiação, como apresentado na Figura 3. Foi aplicado para os três sistemas o potencial de $0,2 \mathrm{~V}$, considerando-se que neste potencial não há geração de corrente proveniente de eletrólise. Como observado na Figura 3, a natureza do eletrólito suporte afetou a intensidade da fotocorrente medida, com menor intensidade para o sistema ITO- $\mathrm{TiO}_{2} / \mathrm{I}^{-}$e maior intensidade para o sistema ITO- $\mathrm{TiO}_{2} / \mathrm{SO}_{4}{ }^{2-}$. Pode ser verificada a baixa afinidade dos íons $\mathrm{SO}_{4}{ }^{2-}$ pela superfície do eletrodo de $\mathrm{ITO}-\mathrm{TiO}_{2}$ comparada com a grande afinidade das moléculas de iodeto, devido à forte adsorção específica deste ânion sobre o eletrodo de trabalho. Uma situação intermediária ocorreu para o sistema $\mathrm{ITO}-\mathrm{TiO}_{2} / \mathrm{Cl}^{-}$.

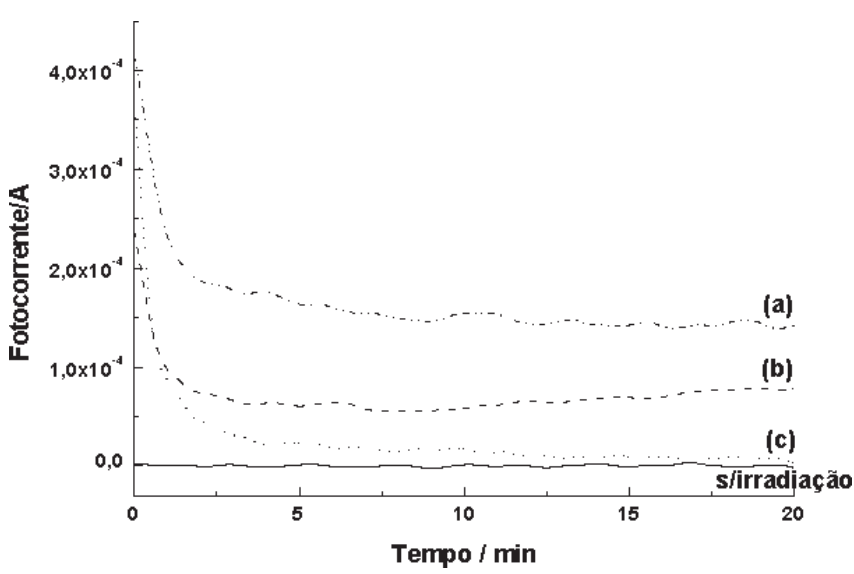

Figura 3. Fotocorrentes dos sistemas ITO-TiO em soluções aquosas contendo (a) $\mathrm{Na}_{2} \mathrm{SO}_{4}$, (b) $\mathrm{KCl}$ ou (c) $\mathrm{KI} 0,1 \mathrm{~mol} \mathrm{~L}^{-1}$, com potencial aplicado de 0,20 V.T $=298 \mathrm{~K}$. Área do eletrodo $=4,65 \mathrm{~cm}^{2}$ e massa de $\mathrm{TiO}_{2}=3,20 \mathrm{mg}$

Para verificar se a atrazina adsorve diretamente na superfície do eletrodo de trabalho ou pode sofrer a ação do eletrólito suporte, atuando como um sítio de adsorção, foram realizadas medidas de fotocorrente na presença do herbicida.

Na Figura 4 observa-se que o valor médio de fotocorrente na presença do herbicida decresce de $15 \mu \mathrm{A}$ em relação ao valor médio obtido pelo sistema ITO- $\mathrm{TiO}_{2}$ em $\mathrm{Na}_{2} \mathrm{SO}_{4}$. Este fato indica que a adsorção do herbicida ocorre, semelhante à ação de adsorção específica do cloreto e iodeto, facilitada pela pouca afinidade dos íons $\mathrm{SO}_{4}^{2-}$ pela superfície do eletrodo de trabalho. Já o valor médio de

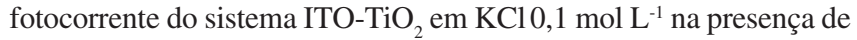
atrazina, apresentado na Figura 5, não mostrou decréscimo, indicando que o eletrólito deve estar competindo ou privilegiando a adsorção da atrazina sobre a superfície do eletrodo de trabalho.

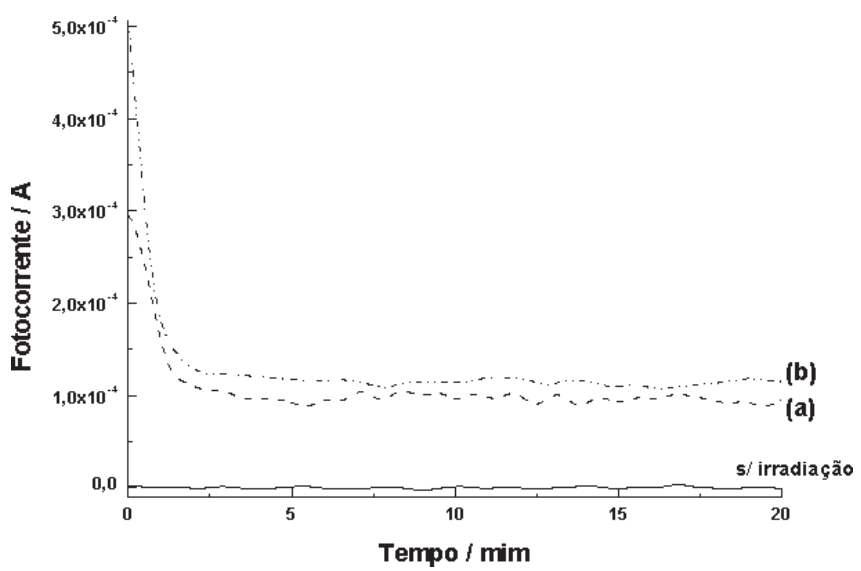

Figura 4. Fotocorrentes do sistema ITO-TiO em $\mathrm{Na}_{2} \mathrm{SO}_{4} 0,1 \mathrm{~mol} \mathrm{~L}^{-1}$ (a) na presença e (b) na ausência de atrazina $5 \times 10^{-5} \mathrm{~mol} \mathrm{~L}^{-1} . T=298 \mathrm{~K}$. Área do eletrodo $=4,65 \mathrm{~cm}^{2}$ e massa de $\mathrm{TiO}_{2}=3,18 \mathrm{mg}$

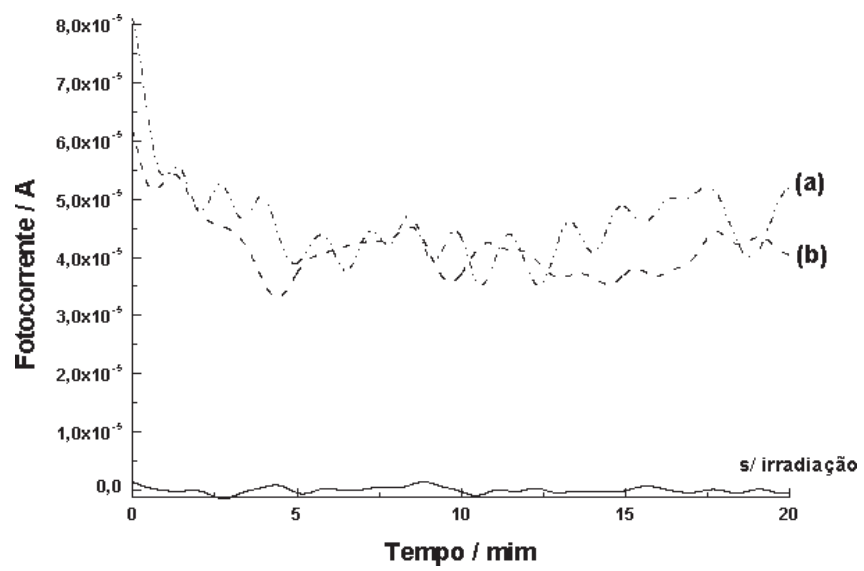

Figura 5. Fotocorrentes do sistema ITO-TiO em $\mathrm{KCl} \mathrm{0,1} \mathrm{mol} \mathrm{L}^{-1}$ (a) na presença e (b) na ausência de atrazina $5 \times 10^{-5} \mathrm{~mol} \mathrm{~L}^{-1} \cdot T=298 \mathrm{~K}$. Área do eletrodo $=4,65 \mathrm{~cm}^{2}$ e massa de $\mathrm{TiO}_{2}=3,15 \mathrm{mg}$

Para verificar se o sistema $\mathrm{ITO}-\mathrm{TiO}_{2} / \mathrm{KCl}$ atua favorecendo ou desfavorecendo a adsorção da atrazina foram estudados diferentes parâmetros através da obtenção, pelas técnicas cromatográficas e espectroscópicas, de dados referentes à degradação e mineralização da atrazina.

Na Tabela 1, é apresentada a matriz experimental elaborada para realização dos experimentos, após estudos prévios deste tema ${ }^{20}$. Através de um planejamento, foi possível otimizar e organizar os experimentos de degradação, de maneira a obter resultados seguros e confiáveis com o menor número de experimentos realizados. Três parâmetros foram analisados: concentração de $\mathrm{KCl}$ (eletrólito), potencial eletroquímico aplicado sobre o eletrodo de trabalho e a espessura de $\mathrm{TiO}_{2}$ depositado sobre a placa de vidro condutor. Foram utilizados $\mathrm{KCl} 1,0 \times 10^{-4}$ e $0,10 \mathrm{~mol} \mathrm{~L}^{-1}$, potencial de 0,4 e $0,8 \mathrm{~V}$ e massa de $\mathrm{TiO}_{2}$ depositado de $\sim 2,0 \mathrm{mg}$ e $\sim 3,0 \mathrm{mg}$. 
Tabela 1. Matrix experimental

\begin{tabular}{cccc}
\hline $\mathrm{n}^{\circ}$. exp. & {$[\mathrm{KCl}]$} & potencial & camadas \\
\hline 1 & - & - & - \\
2 & + & - & - \\
3 & - & + & - \\
4 & + & + & - \\
5 & - & - & + \\
6 & + & - & + \\
7 & - & + & + \\
8 & + & + & + \\
\hline & mol L-1 & $\mathrm{V}$ & $\mathrm{mg}$ \\
- & $1,0 \times 10^{-4}$ & 0,40 & 0,20 \\
+ & 0,10 & 0,80 & 0,30 \\
\hline
\end{tabular}

$\mathrm{n}^{\circ}$ exp. - número do experimento; $[\mathrm{KCl}]$ - concentração de $\mathrm{KCl}$ (eletrólito); potencial - potencial aplicado; mg - massa de $\mathrm{TiO}_{2}$ depositada sobre ITO

Na Figura 6 são apresentados os comportamentos de fotocorrente do sistema $\mathrm{ITO}-\mathrm{TiO}_{2} / \mathrm{KCl}$ durante oito horas de irradiação, na presença do herbicida, nas diferentes condições experimentais descritas na matriz experimental (Tabela 1). Podem ser observados dois agrupamentos distintos, A e B. Estes correspondem aos experimentos ímpares e pares, respectivamente. $\mathrm{O}$ grupo $\mathrm{A}$ apresenta valores de fotocorrente maiores em relação ao do grupo $\mathrm{B}$, demostrando dois comportamentos diferentes de adsorção do herbicida com as variáveis estudadas.

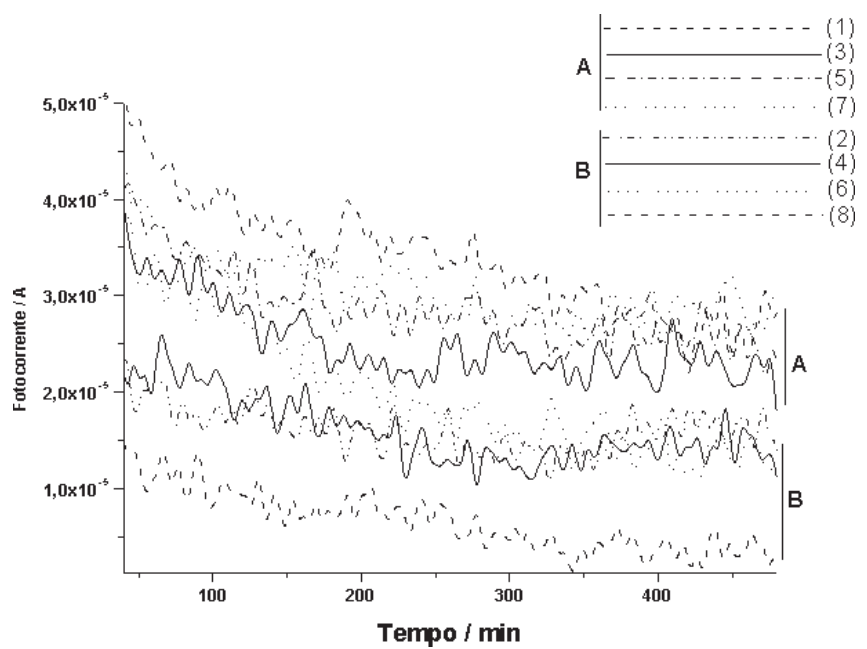

Figura 6. Fotocorrentes do sistema ITO-TiO $/ \mathrm{KCl}$ durante $8 \mathrm{~h}$ de irradiação, na presença de atrazina $5 \times 10^{-5} \mathrm{~mol} \mathrm{L^{-1 }}$, nas diferentes condições descritas na matriz experimental da Tabela 1. Grupo A (impares): (1) $[\mathrm{KCl}]=1,0 x$ $10^{-4} \mathrm{~mol} \mathrm{~L}^{-1} ; 0,40 \mathrm{~V} ; 0,20 \mathrm{mg} \mathrm{de} \mathrm{TiO}_{2} ;(3)[\mathrm{KCl}]=1,0 \times 10^{-4} \mathrm{~mol} \mathrm{~L}^{-1} ; 0,80 \mathrm{~V}$; $0,20 \mathrm{mg}$ de $\mathrm{TiO}_{2} ;(5)[\mathrm{KCl}]=1,0 \times 10^{-4} \mathrm{~mol} \mathrm{~L}^{-1} ; 0,40 \mathrm{~V} ; 0,30 \mathrm{mg}$ de $\mathrm{TiO}_{2}$; (7) $[\mathrm{KCl}]=1,0 \times 10^{-4} \mathrm{~mol} \mathrm{~L}^{-1} ; 0,80 \mathrm{~V} ; 0,30 \mathrm{mg}$ de TiO ; Grupo B (pares): (2) $[\mathrm{KCl}]=0,10 \mathrm{~mol} \mathrm{~L}{ }^{-1} ; 0,40 \mathrm{~V} ; 0,20 \mathrm{mg} \mathrm{de} \mathrm{TiO}{ }_{2} ;(4)[\mathrm{KCl}]=0,10 \mathrm{~mol} \mathrm{~L}^{-1}$; $0,80 \mathrm{~V} ; 0,20 \mathrm{mg} \mathrm{de} \mathrm{TiO}_{2} ;(6)[\mathrm{KCl}]=0,10 \mathrm{~mol} \mathrm{~L}^{-1} ; 0,40 \mathrm{~V} ; 0,30 \mathrm{mg} \mathrm{de} \mathrm{TiO}_{2}$; (8) $[\mathrm{KCl}]=0,10 \mathrm{~mol} \mathrm{~L} \mathrm{~L}^{-1} ; 0,80 \mathrm{~V} ; 0,30 \mathrm{mg}$ de $\mathrm{TiO}_{2} . \mathrm{T}=298 \mathrm{~K}$. Área do eletrodo $=4,65 \mathrm{~cm}^{2}$

Na Tabela 2 são apresentados os resultados de degradação da atrazina e a formação dos produtos de mineralização. As concentrações reais de atrazina foram determinadas, a partir da curva padrão, pela diluição da solução. Nos cromatogramas temporais de atrazina fotodegradada o tempo de retenção para a atrazina foi de 5,8 min (absorção máxima, $220 \mathrm{~nm}$ ). Os dados obtidos pelo cromatograma demonstraram um decaimento exponencial da concentração de atrazina fotodegradada em função do tempo, seguindo um comportamento cinético de pseudo primeira ordem. A partir dos logaritmos das concentrações de atrazina em função do tempo foi obtida uma reta cuja inclinação corresponde à constante de velocidade observada $\left(\mathrm{k}_{\mathrm{obs}}\right)$.

Tabela 2. Resultados de degradação da atrazina e formação dos produtos de mineralização

\begin{tabular}{cccrc}
\hline $\mathrm{n}^{\text {o. exp. }}$ & $\begin{array}{c}\mathrm{k}_{\mathrm{obs}} / \\
10^{-4} \mathrm{~min}^{-1}\end{array}$ & $\mathrm{r}$ & $\begin{array}{c}{\left[\mathrm{NH}_{4}^{+}\right] /} \\
\mu \mathrm{mol} \mathrm{L}\end{array}$ & $\begin{array}{c}{\left[\mathrm{NO}_{3}^{-}\right] /} \\
\mu \mathrm{mol} \mathrm{L}\end{array}$ \\
\hline 1 & 10,50 & 0,99395 & 9,64 & 3,55 \\
2 & 5,51 & 0,99351 & 84,99 & 6,37 \\
3 & 7,69 & 0,99064 & 2,15 & 5,17 \\
4 & 4,76 & 0,99691 & 17,95 & 4,75 \\
5 & 9,90 & 0,97361 & 2,99 & 3,69 \\
6 & 3,37 & 0,98851 & 22,88 & 4,33 \\
7 & 7,84 & 0,99845 & 2,92 & 3,97 \\
8 & 5,04 & 0,99393 & 22,77 & 5,17 \\
\hline
\end{tabular}

$\mathrm{n}^{\circ}$ exp. - número do experimento; $\mathrm{k}_{\mathrm{obs}}$ - constante de velocidade da degradação da atrazina; $r$ - coeficiente de correlação da degradação da atrazina; $\left[\mathrm{NH}_{4}^{+}\right]$-concentração do íon amônio formado após $8 \mathrm{~h}$ de irradiação; $\left[\mathrm{NO}_{3}^{-}\right]$- concentração do íon nitrato formado após $8 \mathrm{~h}$ de irradiação

As constantes de velocidades observadas $\left(\mathrm{k}_{\mathrm{obs}}\right)$ na Tabela 2 apresentam valores no intervalo de $10 \times 10^{-4}$ a $3 \times 10^{-4} \mathrm{~min}^{-1}$, demostrando que os experimentos ímpares tiveram constantes de velocidades de degradação de atrazina superiores às dos experimentos pares. Dados preliminares mostraram que uma espécie intermediária e um produto são possíveis de serem formados neste sistema ${ }^{20}$. O produto observado apresentou tempo de retenção de 2,6 min com absorção máxima entre 220 e $225 \mathrm{~nm}$. O intermediário formado apresentou absorção máxima entre 225 e $230 \mathrm{~nm}$ com tempo de retenção em 3,7 min. Provavelmente estas espécies devem ser formadas devido à clivagem de grupos $\mathrm{Cl}$ e etil da molécula de atrazina e a análise destes seria possível utilizando um CG-MS ${ }^{21}$.

As concentrações dos íons $\mathrm{NO}_{3}^{-}$e $\mathrm{NH}_{4}^{+}$obtidas após $8 \mathrm{~h}$ de irradiação, apresentadas na Tabela 2 , demonstraram que ocorreu mineralização da atrazina. A resposta às variáveis utilizadas não se mostrou adequada para os íons $\mathrm{NO}_{3}^{-}$, dada a baixa concentração formada, mas para os íons $\mathrm{NH}_{4}^{+}$foram constatadas diferentes concentrações entre os resultados obtidos.

A tendência observada, nos resultados da Tabela 2, foi que as maiores concentrações de $\mathrm{NH}_{4}^{+}$foram obtidas nos experimentos pares, onde as mineralizações de atrazina foram superiores aos resultados dos experimentos ímpares. A maior concentração de $\mathrm{NH}_{4}^{+}$foi obtida na mais alta concentração de $\mathrm{KCl}$, menor potencial aplicado e menor espessura do filme de $\mathrm{TiO}_{2}$, demostrando o efeito destes fatores sobre a mineralização da atrazina.

Os resultados obtidos na degradação e mineralização da atrazina, utilizando diferentes parâmetros experimentais, poderiam ser melhor entendidos com auxílio da espectroscopia SERS ("Surface Enhanced Raman Scattering"), considerando que sobre a superfície de $\mathrm{TiO}_{2}$ o efeito SERS deve ocorrer ${ }^{22}$. O estudo de adsorção da atrazina em diferentes concentrações de $\mathrm{KCl}$, potenciais aplicados e espessuras do filme de $\mathrm{TiO}_{2}$ poderia ser monitorado em relação à interação da substância com a superfície. Desta forma, os resultados obtidos na Tabela 2 poderiam ser discutidos em relação a sítios diferentes de adsorção da atrazina sobre o eletrodo de $\mathrm{ITO}-\mathrm{TiO}_{2} / \mathrm{KCl}$; comparáveis, por exemplo, ao trabalho de Rubim ${ }^{23}$, que estudou a adsorção e 
eletroredução de cianopiridinas em eletrodo de prata por SERS. Este pesquisador verificou que estas espécies são adsorvidas perpendicular ou paralelamente à superfície do eletrodo, dependendo do potencial aplicado ao eletrodo e de sua concentração na solução.

\section{CONCLUSÃO}

A principal conclusão deste trabalho é que a natureza do eletrólito suporte afeta a intensidade da fotocorrente, sendo um indicativo do processo de adsorção. A ação fotocatalítica do óxido de titânio/ $\mathrm{Cl}^{-}$ sobre a atrazina dividiu-se em dois grupos distintos, A e B, influenciados pelos parâmetros envolvidos no processo.

Os resultados podem indicar que a degradação da atrazina e a formação do íon $\mathrm{NH}_{4}^{+}$(mineralização) estão associadas a sítios diferentes de adsorção da atrazina, privilegiando em um grupo de condições a degradação da atrazina a espécies que não se mineralizam e, em outro, a formação de espécies minerais.

\section{AGRADECIMENTOS}

Os autores agradecem ao programa PIBIC-CNPq pelas bolsas de estudo, a A. P. S. F. Farias pelas medidas no CLAE, a R. R. Ishiki pelo auxílio nas medidas espectrofotométricas do íon $\mathrm{NH}_{4}^{+}$e a $\mathrm{J}$. Scarmínio, M. C. Solci e I. S. Scarmínio pelas discussões.

\section{REFERÊNCIAS}

1. http://www.epa.gov/pesticides/reregistration/atrazine, acessada em Setembro 2002.

2. Arántegui, J.; Prado, J.; Chamarro, E.; Esplugas, S.; J. Photochem. Photobiol., A 1995, 88, 65.

3. Nogueira, R. F. P.; Jardim, W. F.; Quim. Nova 1998, 21, 69.

4. Maillard-Dupuy, C.; Guillard, C.; Pichat, P.; New J. Chem. 1994, 18, 941.
5. Hidaka, H.; Asai, Y.; Zhao, J.; Nohara, K.; Pelizzetti, E.; Serpone, N.; J. Phys. Chem. 1995, 99, 8244; Mills, A.; Hunte, S. L.; J. Photochem. Photobiol., A 1997, 108, 35; Choi, W.; Termin, A.; Hoffmann, M. R.; J. Phys. Chem. 1994, 98, 1369; Kormann, C.; Bahnemann, D. W.; Hoffmann, M. R.; Environ. Sci. Technol. 1991, 25, 494.

6. Matthews, R. W.; J. Catal. 1988, 112, 264.

7. Sabate, J.; Anderson, M. A.; Kikkawa, H.; Edwards, M.; Hill, Jr. C. G.; J. Catal. 1991, 127, 167.

8. Vinodgopal, K.; Hotchandani, S.; Kamat, P. V.; J. Phys. Chem. 1993, 70, 95.

9. Pelizzetti, E.; Minero, P.; Piccinini, P.; Vicenti, M.; Coord. Chem. Rev. 1993, $125,183$.

10. Bouzaza, A.; Laplanche, A.; J. Photochem. Photobiol., A 2002, 150, 207.

11. Konstantinou, I. K.; Sakkas, V. A.; Albanis, T. A.; Water Res. 2002, 36, 2733.

12. Di Paola, A.; Garcia-Lopez, E.; Ikeda, S.; Marci, G.; Ohtani, B.; Palmisano, L.; Catal. Today 2002, 75, 87.

13. Palombari, R.; Ranchella, M.; Rol, C.; Sebastiani, G. V.; Sol. Energy Mater. Sol. Cells 2002, 71, 359.

14. Jiang, D.; Zhao, H.; Jia, Z.; Cao, J.; John, R.; J. Photochem. Photobiol., A 2001, 144, 197.

15. An, T.; Xiong, Y.; Li, G.; Zha, C.; Zhu, X.; J. Photochem. Photobiol., A 2002, 152, 155.

16. Natarajan, C.; Nogami, G.; J. Electrochem. Soc. 1996, 143, 1547.

17. Nazeeruddin, M. K.; Kay, A.; Rodício, I.; Humphry-Baker, R.; Muller, E.; Liska, P.; Vlachopoulos, N.; Grätzel, M.; J. Am. Chem. Soc. 1993, 115, 6382.

18. Patton, C. J.; Crouch, S. R.; Anal. Chem. 1997, 49, 464.

19. Parsons, T. R.; Maita, Y.; Lalli, C. M.; A manual of chemical and biological methods for seawater analysis, Pergamon Press: Oxford, 1984.

20. Santana, H. de; Bonancea, C. E.; Takashima, K.; Scarmínio, I. S.; Solci, M. C.; Khalaf, P.; Pelicho, A. F.; Yassumoto, L.; Resumos do XLI Congresso Brasileiro de Química, Porto Alegre, Brasil, 2001; Santana, H. de; Bonancea, C. E.; Khalaf, P.; Pelicho, A. F.; Yassumoto, L.; Scarmínio, I. S.; Solci, M. C.; Takashima, K.; Resumos do IX Encontro de Química da Região Sul, Londrina, Brasil, 2001.

21. Pospísil, L.; Trsková, R.; Fuoco, R.; Colombini, M. P.; J. Electroanal. Chem. 1995, 395, 189.

22. Faria, D. L. A.; Temperini, M. L. A.; Sala, O.; Quim. Nova 1999, 22, 541.

23. Rubim, J. C.; J. Electroanal. Chem. 1987, 220, 339. 